\title{
Detection of species and molecular typing of Leishmania in suspected patients by targeting cytochrome $b$ gene in Zahedan, southeast of Iran
}

\author{
Hadi Mirahmadi ${ }^{1,2}$, Nasrin Rezaee ${ }^{1,2}$, Ahmad Mehravaran ${ }^{1,2}$, Peyman Heydarian ${ }^{3}$ and Saber Raeghi ${ }^{4}$
}

1. Infectious Diseases and Tropical Medicine Research Center, Zahedan University of Medical Sciences, Zahedan, Iran; 2. Department of Parasitology and Mycology, Faculty of Medicine, Zahedan University of Medical Sciences, Zahedan, Iran;

3. Department of Medical Parasitology and Mycology, School of Medicine, Qazvin University of Medical Sciences, Qazvin, Iran; 4. Department of Laboratory Sciences, Maragheh University of Medical Sciences, Maragheh, Iran. Corresponding author: Saber Raeghi, e-mail: saberraeghi@gmail.com

Co-authors: HM: hmirahmadi59@gmail.com, NR: Nasrinrezaee1723@gmail.com, AM: ahmadmehravaran55@gmail.com,PH: peiman.heydaryan@yahoo.com

Received: 10-11-2017, Accepted: 23-04-2018, Published online: 26-05-2018

doi: 10.14202/vetworld.2018.700-705 How to cite this article: Mirahmadi H, Rezaee N, Mehravaran A, Heydarian P, Raeghi S (2018) Detection of species and molecular typing of Leishmania in suspected patients by targeting cytochrome $b$ gene in Zahedan, southeast of Iran, Veterinary World, 11(5): 700-705.

\begin{abstract}
Aim: Cutaneous leishmaniasis (CL) is one of the most important health problems that are capable of involving both tropical and subtropical areas, especially in Iran. This cross-sectional study aimed to differentiate the species that are able to cause CL in Zahedan city by polymerase chain reaction-restriction fragment length polymorphism (PCR-RFLP) method.

Materials and Methods: It was conducted on 145 suspected CL patients in Zahedan city between 2014 and 2016. The smears were initially prepared, air-dried, fixed with absolute methanol, and stained with 10\% Giemsa. Then, we examined the stained samples by a light microscope under $1000 \times$ magnifications. PCR assay targeted cytochrome $b($ cyt $b$ ) gene using LCBF1 and LCBR2 primers and the products digested by Ssp1 enzymes.
\end{abstract}

Results: From 145 suspected CL patients, 76 (52.4\%) were positive in microscopic examination. In addition, we detected gene of interest (cyt $b$ ) in 98 (67.5\%). The results of PCR-RFLP indicated that 53/98 (54\%) cases were Leishmania major and 45/98 (46\%) were Leishmania tropica, and the main species in these areas was L. major.

Conclusion: We concluded that the microscopic examination is not sensitive enough and is not able to distinguish between different Leishmania species. Instead, molecular methods like PCR-RFLP can be appropriately used with promising results.

Keywords: cytochrome b, Leishmania major, Leishmania tropica, polymerase chain reaction-restriction fragment length polymorphism.

\section{Introduction}

Leishmaniasis is a parasitic disease caused by various species of protozoa named Leishmania $[1,2]$. Cutaneous leishmaniasis (CL) is one of the 10 important parasitic diseases in tropical areas. The majority of CL cases in the Middle East have been reported from countries such as Afghanistan, Libya, Iraq, Iran, Jordan, Morocco, Saudi Arabia, Syria, Yemen, and Palestine [3]. Annual incidence of human leishmaniasis is estimated to be about 500,000, with 350 million people at the risk of this disease worldwide [4].

In Iran, CL is regarded as a serious health problem and is endemic in both urban and rural areas $[5,6]$. In addition, the annual new cases of CL in Iran are estimated to be 20,000 [7,8]. Zoonotic CL (ZCL) and anthroponotic CL (ACL) are both reported in Iran, mostly caused by Leishmania major and Leishmania

Copyright: Mirahmadi, et al. Open Access. This article is distributed under the terms of the Creative Commons Attribution 4.0 International License (http://creativecommons.org/licenses/ by/4.0/), which permits unrestricted use, distribution, and reproduction in any medium, provided you give appropriate credit to the original author(s) and the source, provide a link to the Creative Commons license, and indicate if changes were made. The Creative Commons Public Domain Dedication waiver (http:// creativecommons.org/publicdomain/zero/1.0/) applies to the data made available in this article, unless otherwise stated. tropica, respectively [9]. ZCL is endemic in various regions such as south-west and central of Iran with a high incidence rate and different reservoir hosts [10]. Due to differences in preventing and controlling methods used, clinical course, prognosis, and the method of treatment in applied against different species; the identification of species is of particular importance. Notably, L. major and L. tropica are morphological identical so that parasitological methods are not able to distinguish them from each other [11]. However, isoenzyme technique is a gold standard for differentiation of species, whereas molecular techniques are more expensive and time-consuming [12]. Polymerase chain reaction-restriction fragment length polymorphism (PCR-RFLP) has been suggested as an applicable molecular method for detecting and distinguishing different species of Leishmania [13-16]. Sistan and Baluchestan (a province in southeast Iran) are one of the most important endemic foci of disease [4,17].

Although there is a high prevalence of disease reported in these areas, identification of species has not yet been fully accomplished. Therefore, the present study attempted to differentiate the species of Leishmania that are capable of causing CL in Zahedan city by PCR-RFLP method. 
This cross-sectional study aimed to differentiate the species that are able to cause CL in Zahedan city by PCR-RFLP method.

\section{Materials and Methods \\ Ethical approval}

This research was approved by the Faculty of Medicine, Zahedan University of Medical Sciences, Zahedan, Iran.

\section{Sampling and microscopic examination}

This cross-sectional study was conducted on 145 suspected CL cases in Zahedan between 2014 and 2016. Data of cases were received from the health centers, and then their skin lesions were collected. These data consisted of the occupation, place of residence, type, number and location of lesions, were included in a questionnaire. Exudate smears were prepared, air-dried, fixed with absolute methanol, and stained with $10 \%$ Giemsa in a $\mathrm{pH}$ of 7.4 phosphate buffer for $20 \mathrm{~min}$ and examined by a light microscope under 1000× magnifications [18].

\section{DNA extraction}

DNA was extracted from Giemsa stained slides with the High Pure PCR Template Purification (Takapouzist, Iran DynaBio Blood/Tissue Genomic DNA Extraction Kit) regarding the manufacturer's procedure. The extracted DNA was stored at $-20^{\circ} \mathrm{C}$ until the time of use.

\section{PCR assay}

cyt $b$ gene was amplified with a pair specific primers LCBF1 (5'GGTGTAGGTTTTAGTTT AGG3') and LCBR2 (5' CTACAATAAACAAAT CATAATATACAATT3'). The total volume of the reaction was $30 \mu \mathrm{l}$ containing $3 \mu \mathrm{l}$ DNA templates, $15.5 \mu 1$ distilled water, $1 \mu 1$ of each primer (forward and reverse), and $9.5 \mu 1$ master mix (amplicon). PCR program used in the Thermocycler device (Eppendorf Mastercycler Gradient) was as follows: $95^{\circ} \mathrm{C}$ for 5 min (initial denaturation) followed by 35 cycles of these steps: $94^{\circ} \mathrm{C}$ for $45 \mathrm{~s}, 50^{\circ} \mathrm{C}$ for $1 \mathrm{~min}, 72^{\circ} \mathrm{C}$ for $1 \mathrm{~min}$, and $72^{\circ} \mathrm{C}$ for $5 \mathrm{~min}$.

Subsequently, $5 \mu \mathrm{L}$ of PCR products was transferred into the $1.5 \%$ agarose gel (stained with ethidium bromide), and visualized by ultraviolet illumination. Finally, products with $880 \mathrm{bps}$ length were considered as positive.

\section{PCR-RFLP}

The Ssp1 enzymes were used to digest the PCR products in RFLP, $10 \mu \mathrm{l}$ of PCR product, $1 \mu \mathrm{l}$ of supplied restriction enzyme buffer, $1 \mu$ of restriction enzyme diluted, and D.W up to $30 \mu 1$ were provided for RFLP, according to enzyme directory. Subsequently, tubes were incubated at $37^{\circ} \mathrm{C}$ for $7 \mathrm{~h}$. Digestion products were separated using $1.5 \%$ agarose gels in TAE buffer and visualized after staining by gel red.

\section{DNA sequencing and phylogenetic analysis}

To confirm the diagnosis of species, PCR products were purified using PCR purification kit (Bioneer,
Korea) and sequenced from both directions (Applied Biosystems, DNA Analyzers Sequencing, Bioneer, Korea, Sanger method), using the same primers as what used in the PCR. A neighbor-joining tree was gathered using the MEGA6 software. Results obtained and compared with the information presented in NCBI GenBank.

\section{Results}

From 145 suspected CL patients (infected in different parts of Zahedan), 76 (52.4\%) were positive in microscopic examinations, and $98(67.5 \%)$ of samples were positive for cyt $b$ gene in PCR. The distribution of patients according to diagnostic techniques is summarized in Table-1.

The results of PCR-RFLP indicated that 53/98 (54\%) of cases were L. major and 45/98 (46\%) were $L$. tropica. The main species in these areas were also shown to be L. major. Results are shown in Figure-1.

Of 53 samples of L. major, the most frequent lesions were on hands (26.4\%), feet $(20 / 4 \%)$, and face $(15 / 1 \%)$, respectively. While of 45 samples of $L$. tropica, the most frequent related lesions were on hands $(28.9 \%)$, face $(20 \%)$, and feet $(15 / 6 \%)$, respectively (Table-2).

Another finding of this study was the number of lesions on each patient's body. Of 53 cases with L. major had one lesion $(49.1 \%)$ are the most frequent lesion then two and $18.9 \%$ had three lesions. Similarly, out of the 45 samples (51.1\%) of the L. tropica showed one lesion on their body, while in $15.9 \%$ and $8.9 \%$ of cases there were two and three lesions, respectively. These results are shown in Table-3.

Table-1: The distribution of patients according to diagnostic technique.

\begin{tabular}{lcc}
\hline \multirow{2}{*}{ Technique } & \multicolumn{2}{c}{ Result } \\
\cline { 2 - 3 } & Positive (\%) & Negative (\%) \\
\hline Microscopic & $76(52.41)$ & $69(47.59)$ \\
PCR & $98(67.58)$ & $47(32.42)$ \\
\hline
\end{tabular}

PCR: Polymerase chain reaction

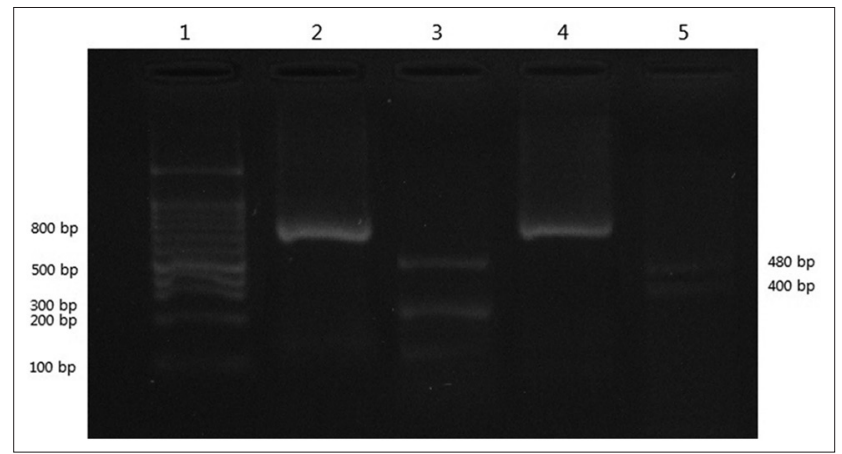

Figure-1: Restriction fragment length polymorphism patterns obtained from Leishmania stocks and Giemsastained smears. Lane 1. 100-bp size marker (fermentas); Lane 2. 4 Cyt $b$ - polymerase chain reaction banding patterns (880 bp); Lane 3. Leishmania tropica (130 bp, 215 bp, 535 bp); Lane 4. Leishmania major (400 bp, 480 bp). 
Results of cyt $b$ sequencing of both L. major isolated from patients in Zahedan were compared with that of $L$. major isolates (cyt $b$ gene) submitted in the GenBank using Multalin online software. These results are presented in Figure-2.

In the one isolate of $L$. major, there were five nucleotide changes between cyt $b$, predominantly in the third place of nucleotide codons (Wobble site) that did not lead to new amino acid creation.
The isolates were then phylogenetically analyzed, based on the maximum likelihood method and using both the Tamura 2-parameter model sequences (obtained in this study) and the GenBank reference sequences (using the MEGA 6.0 Software) (Figure-3). A validation value $70 \%$ with a degree of confidence of $95 \%$ for topology in each branch was considered as acceptable. Trypanosoma brucei with access numbers cytochrome b: M94286 as the outside group was considered.

Table-2: The distribution of patients according to the location of lesions.

\begin{tabular}{|c|c|c|c|c|c|c|c|c|c|c|c|c|c|}
\hline \multirow[t]{2}{*}{$\begin{array}{l}\text { Type of } \\
\text { parasite }\end{array}$} & \multicolumn{13}{|c|}{$\begin{array}{c}\text { Location of lesion } \\
\text { n (\%) }\end{array}$} \\
\hline & Face & Hand & Feet & $\begin{array}{l}\text { Hand } \\
\text { and } \\
\text { face }\end{array}$ & $\begin{array}{l}\text { Hand } \\
\text { and } \\
\text { trunk }\end{array}$ & Trunk & $\begin{array}{c}\text { Hand } \\
\text { and feet }\end{array}$ & Body & $\begin{array}{l}\text { Head } \\
\text { and } \\
\text { face }\end{array}$ & Nose & $\begin{array}{l}\text { Face } \\
\text { and } \\
\text { arms }\end{array}$ & $\begin{array}{l}\text { Head } \\
\text { and } \\
\text { hand }\end{array}$ & Total \\
\hline L. major & $8(15.1)$ & $14(26.4)$ & $11(20.7)$ & $2(3.8)$ & $2(3.8)$ & $5(9.4)$ & $2(3.8)$ & $6(11.3)$ & $2(3.8)$ & $0(0.0)$ & $0(0.0)$ & $1(1.9)$ & $53(100.0)$ \\
\hline L. tropica & $9(20.0)$ & $13(28.9)$ & 7 (15.7) & $1(2.2)$ & $1(2.2)$ & $2(4.4)$ & $2(4.4)$ & $1(2.2)$ & $6(13.4)$ & $1(2.2)$ & $1(2.2)$ & $1(2.2)$ & $45(100.0)$ \\
\hline Negative & $3(6.4)$ & $12(25.5)$ & $11(23.4)$ & $2(4.3)$ & $1(2.1)$ & $5(10.6)$ & $0(0.0 \%)$ & $3(6.4)$ & $0(0.0)$ & $0(0.0)$ & $10(21.3)$ & $0(0.0)$ & $47(100.0)$ \\
\hline Total & $20(13.8)$ & 39 (26.9) & $29(20.0)$ & $5(3.4)$ & $4(2.8)$ & $12(8.3)$ & $4(2.8)$ & $10(6.9)$ & $8(5.5)$ & $1(0.7)$ & $11(7.5)$ & $2(1.4)$ & $145(100.0)$ \\
\hline
\end{tabular}

Table-3: Distribution of patients based on the number of lesions.

\begin{tabular}{|c|c|c|c|c|c|c|c|c|c|c|c|}
\hline \multirow{2}{*}{$\begin{array}{l}\text { Type of } \\
\text { parasite }\end{array}$} & \multicolumn{11}{|c|}{ Number of lesions } \\
\hline & 0* & 1 & 2 & 3 & 4 & 5 & 6 & 9 & 10 & 12 & Total \\
\hline$(\%)$ & $(57)$ & $26(4$ & 10 & $10(1 \varepsilon$ & 2 & $1(1$ & $1(1$ & $0(0.0)$ & $0(0.0)$ & $0(0.0)$ & $53(100.0)$ \\
\hline L. tropica n (\%) & $3(6.7)$ & $23(51.1)$ & $7(15.6)$ & $4(8.9)$ & $3(6.7)$ & $1(2.2)$ & $0(0.0)$ & $1(2.2)$ & $3(6.7)$ & $0(0.0)$ & $45(100.0)$ \\
\hline Negative $n(\%)$ & $9(19.1)$ & $25(53.2)$ & $2(4.3)$ & $4(8.5)$ & $1(2.1)$ & $1(2.1)$ & $2(4.3)$ & $1(2.1)$ & $1(2.1)$ & $1(2.1)$ & $47(100.0)$ \\
\hline Total n (\%) & $15(10.3)$ & $74(51.0)$ & $19(13.1)$ & $18(12.4)$ & $6(4.1)$ & $3(2.1)$ & $3(2.1)$ & $2(1.4)$ & $4(2.8)$ & $1(0.7)$ & $145(100.0)$ \\
\hline
\end{tabular}

*The purpose of this number was old wounds or wounds that were not active lesions and secretions and serosity were lacking, L. tropica=Leishmania tropica, L. major=Leishmania major

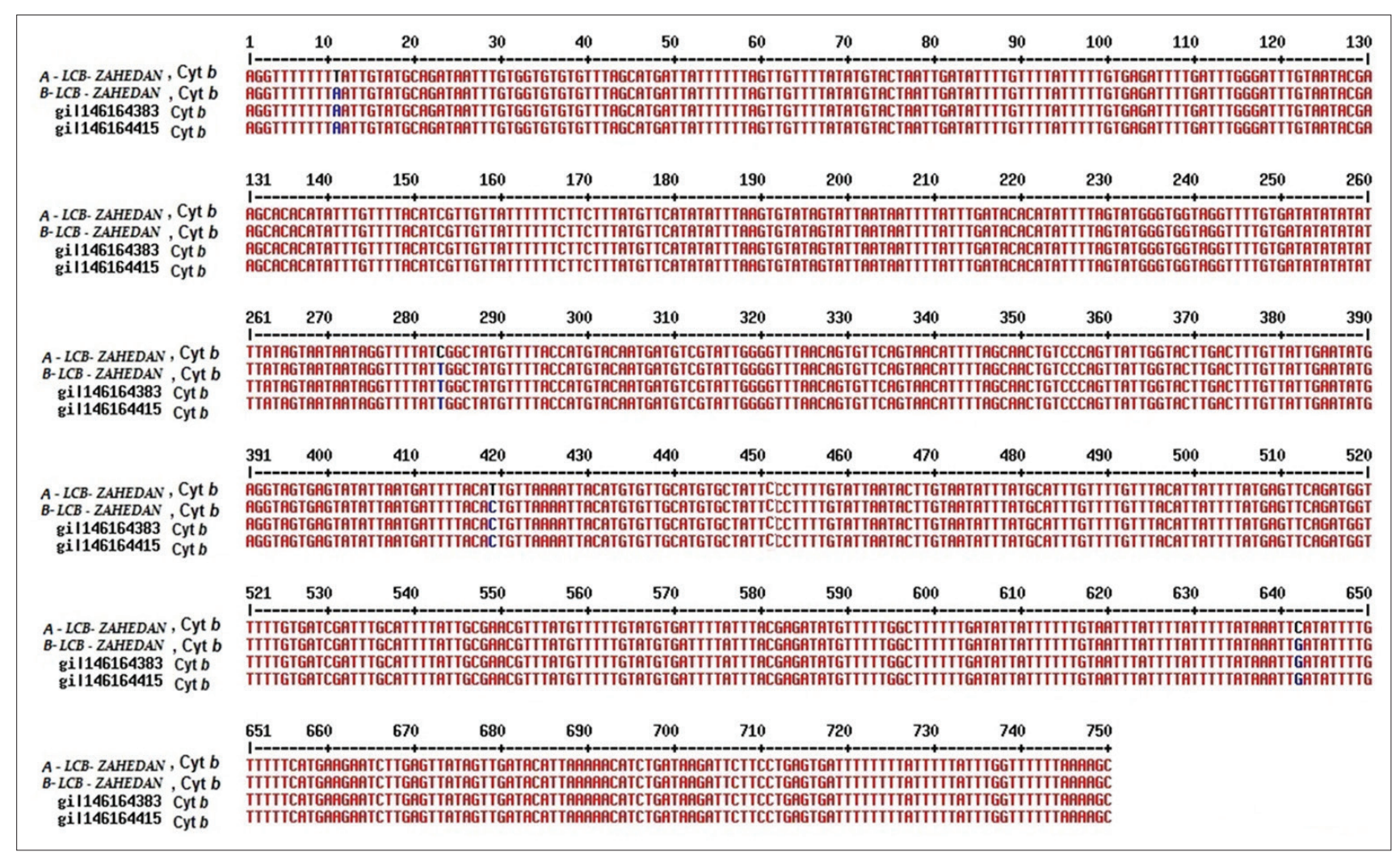

Figure-2: Comparison of cytochromes b gene sequences in Leishmania major isolates. 


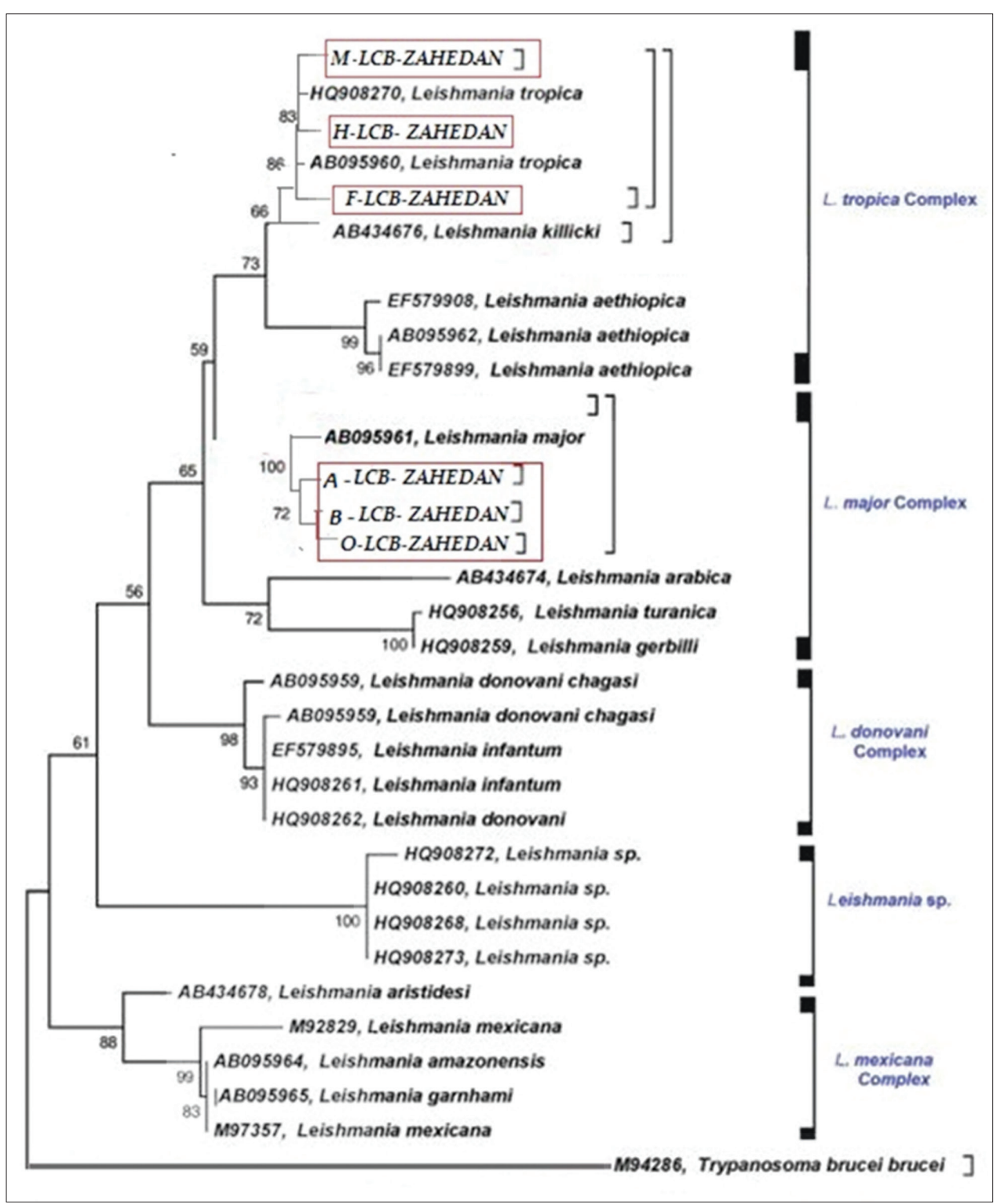

Figure-3: Leishmania major and Leishmania tropica (isolated from suspected cases in Zahedan) phylogenetic trees Trypanosoma brucei were considered as outside groups. The samples of this study are marked with different colored shapes. The rest of related to standard samples are prepared from the GenBank.

\section{Discussion}

Leishmania is a parasitological disease with symptoms ranging from a mild cutaneous to a lethal visceral form. 12 million people in 88 countries are estimated to be suffering from this group of diseases [19]. CL is the most common form of disease worldwide. The CL is endemic in Iran, and about 20,000 new cases are reported annually from different parts of Iran [9].

Sistan and Baluchestan are one of the most important endemic foci of ACL and ZCL. Recently, there is an increasing rate of CL cases reported from this area [20]. This province has geographical importance because of the business, tourism, and exchanging visitors from neighboring countries. Zahedan is the old foci of CL in Iran. A vast majority of cases occur in this area due to the migration of people from villages across the border of Afghanistan and Pakistan [7,21]. In addition, for the reason of geographical feature of these villages and also being in the vicinity of residential areas with rodent's nests, as well as the type of materials used in the construction of houses, barns, etc., they are regarded as ideal places for proliferation of sandflies and contribute to the distribution of disease. Due to the lack of a comprehensive study in these areas, the primary cause of the disease has been remained unclear since different procedures need to be used for preventing and controlling the CL, identification of the species is essential [22].

Sometimes, the traditional and microscopic examination methods used to detect species are not able to differentiate the species of parasites because of similarity in morphological features [23]. Isoenzyme is known as a gold standard method to distinguish between Leishmania species, but unfortunately, this method is expensive and time-consuming [24].

Molecular methods such as PCR-RFLP are valuable tools for differentiating of parasites that used in 
different microorganisms such as zoonotic worms and protozoa as Leishmania species and have been used in numerous studies [25-29].

There are various genetic markers suggested to be useful in molecular identification of Leishmania species including ITS, glycoprotein 63, mini-exon, kinetoplast DNA (kDNA), heat-shock proteins, cysteine protease $\mathrm{B}$, cytochrome oxidase II, and the cyt $b$ genes [30-32]. Cyt $b$ gene, a fragment with high stability, is located in the mitochondrial genome of Leishmania spp. and has been widely used to identify genetic variations among the different species. In addition, this gene has shown to be beneficial in phylogenetic studies [33] and also is effective in phylogenetic studies [34]. This study applied PCR-RFLP method to define Leishmania species for not only arranging precise control platform precisely but also curing patients competently.

In the current study, from 145 CL-suspected cases in different parts of Zahedan City, 76 (52.4\%) of them were positive in the microscopic examination, while in cytochrome b PCR 98 (67.5\%) samples were positive. In a study conducted by Rasti, from 130 suspected CL patients, 87 (66.9\%) cases were positive in the microscopic examination, and when using kDNA PCR 98 (75.4\%) and nested PCR $96(73.8 \%)$ cases were positive [35]. The results of PCR-RFLP indicated that 53/98 (54\%) cases were L. major and 45/98 (46\%) L. tropica and the main species in these areas was L. major, similar to the previous study performed in Mirjaveh, Sistan, and Baluchestan province [25]. In an attempt to identify the cutaneous and visceral leishmaniasis agents by molecular tests in specimens obtained from different geographical areas of Iran, the major cause of CL in Khuzestan, Ilam, Kermanshah, and Semnan (similarly to our study) was shown to be L. major, in Kurdistan province L. tropica and, in Tehran, North Khorasan, Esfahan, Kerman, Fars, and Razavi Khorasan; both species (L. tropica and L. major) of Leishmania were detected [2].

L. major as the main cause of CL in southern areas of Pakistan (bordering to Iran and Sistan and Baluchestan province) [36,37]. Besides, we showed that Sistan and Baluchestan are one of the most important foci of CL and resemble results presented in the previous study, L. major is the dominant cause of CL. In addition, to providing conventional control programs such as control the reservoir and vectors, it is crucial to monitor the migration of Pakistani immigrants and prevents the illegal traveling.

\section{Conclusion}

The results of this study revealed that microscopic examination is not sensitive enough and is not a useful method in distinguishing different species of leishmaniasis. Instead, molecular approach such as PCR-RFLP can be widely used for this goal. Besides, our results showed that Sistan and Baluchestan are one of the important foci of CL and as were mentioned in a previous study in these areas, L. major is the dominant cause of CL. Moreover, to the using conventional control programs such as control the reservoir and vectors, it is crucial to monitor the migration of Pakistani immigrants and prevents of illegal traveling.

\section{Authors' Contributions}

HM assisted in the execution. NR attempted in the acquisition of data by laboratory techniques. SR and AM have designed, planned, and conducted this research. PH analyzed and interpreted the data. All authors have read and approved the final version of the manuscript.

\section{Acknowledgments}

Special thanks to Dr. Bahman Rahimi Esboei for editing the article all laboratory staff of Zahedan University of Medical Sciences. This study was performed as part of MSc student thesis of Nasrin Rezaee, and it was financially supported by the Grant No. 1964, provided from Zahedan University of Medical Sciences, Zahedan, Iran.

\section{Competing Interests}

The authors declare that they have no competing interest.

\section{References}

1. Alvar, J., Vélez, I.D., Bern, C., Herrero, M., Desjeux, P., Cano, J., Jannin, J., den Boer, M. and Team, W.L.C. (2012) Leishmaniasis worldwide and global estimates of its incidence. PLoS One, 7: e35671.

2. Naeem, A.T., Mahmoudi, S., Saboui, F., Hajjaran, H., Pourakbari, B., Mohebali, M., Zarkesh, M.R. and Mamishi, S. (2014) Clinical features and laboratory findings of visceral leishmaniasis in children referred to children medical center hospital, Tehran, Iran during 20042011. Iran J. Parasitol., 9: 1.

3. Postigo, J.A.R. (2010) Leishmaniasis in the world health organization eastern Mediterranean region. Int. J. Antimicrob. Agents, 36: S62-S65.

4. Yaghoobi-Ershadi, M., Zahraei-Ramazani, A., Akhavan, A., Jalali-Zand, A., Abdoli, H. and Nadim, A. (2005) Rodent control operations against zoonotic cutaneous leishmaniasis in rural Iran. Ann. Saudi Med., 25: 309-312.

5. Ashford, R.W. (1996) Leishmaniasis reservoirs and their significance in control. Clin. Dermatol., 14: 523-532.

6. Moghaddas, E., Khamesipour, A., Mohebali, M. and Fata, A. (2017) Iranian native plants on the treatment of cutaneous leishmaniasis: A narrative review. Iran J. Parasitol., 12: 312-322.

7. Fakhar, M., Karamian, M., Ghatee, M.A., Taylor, W.R., Pazoki, G.H. and Rasooli, S.A. (2017) Distribution pattern of anthroponotic cutaneous leishmaniasis caused by Leishmania tropica in Western Afghanistan during 20132014. Acta Trop., 176: 22-28.

8. Mohebali, M., Arzamani, K., Zarei, Z., Akhoundi, B., Hajjaran, H., Raeghi, S., Heidari, Z., Motavalli-Haghi, S.M., Elikaee, S. and Mousazadeh-Mojarrad, A. (2016) Canine visceral leishmaniasis in wild canines (fox, jackal, and wolf) in northeastern Iran using parasitological, serological, and molecular methods. J. Arthropod. Borne Dis., 10: 538.

9. Shirzadi, M., Esfahania, S., Mohebalia, M., Ershadia, M., Gharachorlo, F., Razavia, M. and Postigo, J. (2015) Epidemiological status of leishmaniasis in the Islamic 
Republic of Iran, 1983-2012/situation epidemiologique de la leishmaniose en republique islamique d'Iran, 1983-2012. East Mediterr. Health J., 21: 736.

10. Farahmand, M., Nahrevanian, H., Shirazi, H.A., Naeimi, S., Farzanehnejad, Z. (2011) An overview of a diagnostic and epidemiologic reappraisal of cutaneous leishmaniasis in Iran. Braz. J. Infect. Dis., 15: 17-21.

11. Foroutan, M., Khademvatan, S., Majidiani, H., Khalkhali, H., Hedayati-Rad, F., Khashaveh, S. and Mohammadzadeh, H. (2017) Prevalence of Leishmania species in rodents: A systematic review and meta-analysis in Iran. Acta Trop., 172: 164-172.

12. Mirzaei, A., Rouhani, S., Kazerooni, P., Farahmand, M. and Parvizi, P. (2013) Molecular detection and conventional identification of Leishmania species in reservoir hosts of zoonotic cutaneous leishmaniasis in Fars Province, South of Iran. Iran J. Parasitol., 8: 280.

13. Kheirandish, F., Sharafi, A.C., Kazemi, B., Bandehpour, M., Javad, T.M., Khamesipour, A. (2013) First molecular identification of Leishmania species in a new endemic area of cutaneous leishmaniasis in Lorestan, Iran. Asian Pac. J. Trop. Med., 6: 713-717.

14. Reithinger, R. and Dujardin, J.C. (2007) Molecular diagnosis of leishmaniasis: Current status and future applications. J. Clin. Microbiol., 45: 21-25.

15. Shiee, M.R., Mohebali, M., Doroodgar, A., Teimouri, A., Afzali, H. and Shirzadi, M.R. (2012) A molecular and parasitological survey on cutaneous leishmaniasis patients from historical city of Kashan in Isfahan province, center of Iran. Asian Pac. J. Trop. Dis., 2: 421-425.

16. Yehia, L., Adib-Houreih, M., Raslan, W.F., Kibbi, A.G., Loya, A., Firooz, A., Satti, M., El-Sabban, M. and Khalifeh, I. (2012) Molecular diagnosis of cutaneous leishmaniasis and species identification: Analysis of 122 biopsies with varied parasite index. J. Cutan. Pathol., 39: 347-355.

17. Moaddeb, A., Gettner, S. and Ardehali, S. (1993) Studies on the causative agent of cutaneous leishmaniasis in Shiraz Iran. Iran J. Med. Sci., 18: 2.

18. Machado-Alba, J.E., García-Betancourt, S. and Medina-Morales, D.A. (2016) Leishmaniasis in an infant. An unusual presentation of a forgotten disease. Infection, 20: $165-168$.

19. Singh, N. (2006) Drug resistance mechanisms in clinical isolates of Leishmania donovani. Indian J. Med. Res., 123: 411.

20. Hamid, K., SaiedReza, N., Mehdi, M. and Ezat-Aldin, J. (2012) Molecular characterization of Leishmania infection in sand flies from Sistan Va Baluchistan Province, southeastern Iran. Jundishapur J. Microbiol., 2: 430-431.

21. Gharekhani, J., Heidari, H., Hajian-Bidar, H., Abbasi-Doulatshahi, E. and Edalati-Shokat, H. (2016) Prevalence of anti-Leishmania infantum antibodies in dogs from West of Iran. J. Parasit. Dis., 40(3): 964-967.

22. Schönian, G., Nasereddin, A., Dinse, N., Schweynoch, C., Schallig, H.D., Presber, W. and Jaffe, C.L. (2003) PCR diagnosis and characterization of Leishmania in local and imported clinical samples. Diagn. Microbiol. Infect. Dis., 47: 349-358.

23. Raeghi, S., Sedeghi, S., Sedeghi, S. (2011) Prevalence of Toxoplasma gondii antibodies in cats in Urmia, northwest of Iran. J. Anim. Plant Sci., 21: 132-134.

24. Boggild, A.K., Miranda-Verastegui, C., Espinosa, D., Arevalo, J., Martinez-Medina, D., Llanos-Cuentas, A. and Low, D.E. (2008) Optimization of microculture and evaluation of miniculture for the isolation of Leishmania parasites from cutaneous lesions in Peru. Am. J. Trop. Med. Hyg., 79: 847-852.

25. Fazaeli, A., Fouladi, B., Hashemi-Shahri, S. and Sharifi, I. (2008) Clinical features of cutaneous leishmaniasis and direct PCR-based identification of parasite species in a new focus in southeast of Iran. Iran J. Public Health, 37: 44-51.

26. Jombo, G. and Gyoh, S. (2010) Unusual presentations of cutaneous leishmaniasis in clinical practice and potential challenges in diagnosis: A comprehensive analysis of literature reviews. Asian Pac. J. Trop. Med., 3: 917-921.

27. Reaghi, S., Haghighi, A., Harandi, M.F., Spotin, A., Arzamani, K. and Rouhani, S. (2016) Molecular characterization of Fasciola hepatica and phylogenetic analysis based on mitochondrial (nicotiamide adenine dinucleotide dehydrogenase subunit I and cytochrome oxidase subunit I) genes from the North-East of Iran. Vet World, 9: 1034-1038.

28. Tavares, R., Staggemeier, R., Borges, A., Rodrigues, M., Castelan, L., Vasconcelos, J., Anschau, M. and Spalding, S.M. (2011) Molecular techniques for the study and diagnosis of parasite infection. J. Venom. Anim. Toxins. Incl. Trop. Dis., 17: 239-248.

29. Yavar, R., Abedin, S., Reza, A.M., Ali, O.M., Sina, R., Mehdi, M., Reza, Y.E.M., Fatemeh, M. and Babak, F. (2011) Phlebotomus papatasi and Meriones libycus as the vector and reservoir host of cutaneous leishmaniasis in Qomrood District, Qom Province, central Iran. Asian Pac. J. Trop. Med., 4: 97-100.

30. Fraga, J., Montalvo, A.M., Van der Auwera, G., Maes, I., Dujardin, J.C. and Requena, J.M. (2013) Evolution and species discrimination according to the Leishmania heat-shock protein 20 gene. Infect. Genet. Evol., 18: 229-237.

31. Garcia, L., Kindt, A., Bermudez, H., Llanos-Cuentas, A., De Doncker, S., Arevalo, J., Tintaya, K.W.Q. and Dujardin, J.C. (2004) Culture-independent species typing of neotropical Leishmania for clinical validation of a PCRbased assay targeting heat shock protein 70 genes. J. Clin. Microbiol., 42: 2294-2297.

32. Luis, L., Ramírez, A., Aguilar, C.M., Eresh, S., Barker, D.C. and Mendoza-León, A. (1998) The genomic fingerprinting of the coding region of the $\beta$-tubulin gene in Leishmania identification. Acta Trop., 69: 193-204.

33. Marfurt, J., Niederwieser, I., Makia, N.D., Beck, H.P. and Felger, I. (2003) Diagnostic genotyping of old and new world Leishmania species by PCR-RFLP. Diagn. Microbiol. Infect. Dis., 46: 115-124.

34. Luyo-Acero, G., Uezato, H., Oshiro, M., Takei, K., Kariya, K., Katakura, K., Gomez-Landires, E., Hashiguchi, Y. and Nonaka, S. (2004) Sequence variation of the cyt $b$ gene of various human-infecting members of the genus Leishmania and their phylogeny. Parasitology, 128: 483-491.

35. Rasti, S., Ghorbanzadeh, B., Kheirandish, F., Mousavi, S.G., Pirozmand, A., Hooshyar, H. and Abani, B. (2016) Comparison of molecular, microscopic, and culture methods for diagnosis of cutaneous leishmaniasis. J. Clin. Lab. Anal., 30: 610-615.

36. Bhutto, A.M., Soomro, F.R., Baloch, J.H., Matsumoto, J., Uezato, H., Hashiguchi, Y. and Katakura, K. (2009) Cutaneous leishmaniasis caused by Leishmania (L.) major infection in Sindh province, Pakistan. Acta Trop., 111: 295-298.

37. Bhutto, A.M., Soomro, R.A., Nonaka, S. and Hashiguchi, Y. (2003) Detection of new endemic areas of cutaneous leishmaniasis in Pakistan: A 6-year study. Int. J. Dermatol., 42: $543-548$. 